\title{
Hemi Retinal Vein Occlusion a Particular Form of Retinal Vein Occlusion
}

\author{
Khanaouchi N*, Mouzarii Y, Reda K and Oubaaz \\ A \\ Hopital Militaire d'instruction Mohamed V de Rabat, \\ Morocco \\ *Corresponding author: Nawal Khanaouchi, Hopital \\ Militaire d'instruction Mohamed V de Rabat, Morocco
}

Received: J une 01, 2021; Accepted: J une 21, 2021.

Published: J une 28, 2021

\section{Clinical Image}

We report a case of 55-year-old women, with a medical history of hypertension and diabetes, who complained of a sudden loss of vision of her left eye. Her VA was less than 20/200; slit lamp and gonioscopy were unremarkable. Dilated fundus examination had shown an Aspect of HRVO with a Thunder of flame shaped retinal hemorrhages covering the inferior half of the retina, tortuous veins and cotton-wool spots.

AGF confirmed the venous occlusion caused by delaying the filling of the involved vein, and presence of tortuous veins and extensive hemorrhages in the inferior half of the retina (Figure 1). Oct highlighted the Cystoid macular edema (Figure 2).

Retinal Vein Occlusion (RVO) is the most common retinal vascular disease after diabetic retinopathy [1]. Most of the published studies distinguish two types of RVO: CRVO and BRVO. A further type called Hemi-Retinal Vein Occlusion (HRVO) was considered as far as a simply variant of BRVO, is currently defined as a particular form of CRVO [2].

HCRVO is a distinct entity that is clinically and pathogenetically closely related to CRVO [3]. It has been shown that dual trunk Central Retinal Vein (CRV) occurs in 20.3 per cent of a normal population [4]. HRVO involves occlusion of one of the two trunks, as described above. Half of the retinal surface is thus affected by this occlusion.

Patients usually complain of sudden, painless, unilateral loss of vision. Generally, the profound visual impairment is due to macular edema. Fundus clinical features of HCRVO are similar to those of $\mathrm{CVO}$; however, they remain confined to one-half of retinal surface corresponding to the occluded trunk. HCRVO is characterized with flame-shaped, dot or blot retinal hemorrhages, dilated tortuous veins with or without optic disc edema, hard exudates, cotton-wool spots and macular edema.

HRVO is divided in ischemic and non-ischemic type [5]. Neovascular complications, occurs in ischemic form of HRVO, such as Neovascularization of retina and/or optic disc and/or rubeosis iridis. Eventually, late complications are vitreous hemorrhages, retinal detachment, neovascular glaucoma.

Common risk factor for retinal vein occlusion is advancing
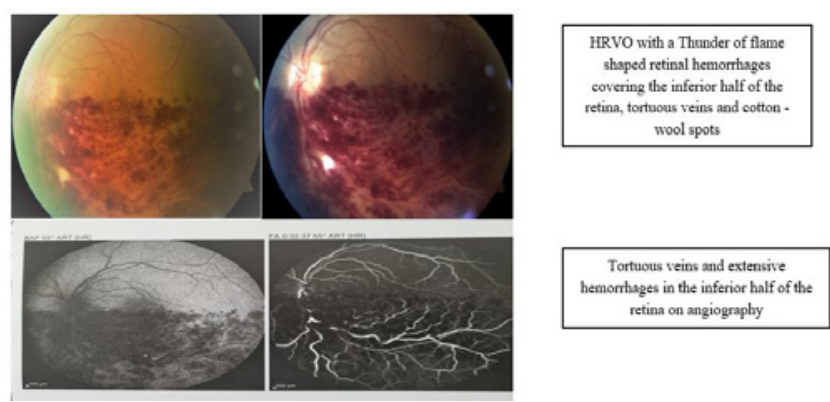

Figure 1: Tortuous veins and extensive hemorrhages in the inferior half of Retina.
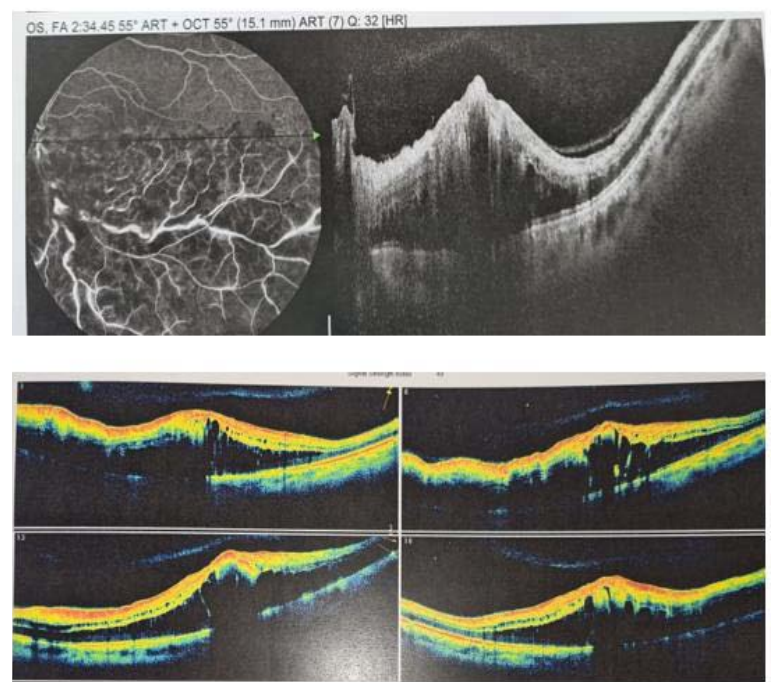

Figure 2: Cystoid Macular Edema on Oct.

age, and additional risk factors include systemic conditions such as hypertension, arteriosclerosis, diabetes mellitus, hyperlipidemia, vascular cerebral stroke. However, blood hyper viscosity and thrombophilia are more frequent in younger patients with HRVO. Ophthalmic risk factors for retinal vein occlusion are ocular hypertension and glaucoma, higher ocular perfusion pressure and changes in the retinal arteries [5].

The management of HRVO depends on the type of the HRVO whether it is an ischemic or non-ischemic form, it is a treatment of complications such as macular edema and neovascularization. The most effective treatments are intravitreal injections of Anti-VEGF or corticosteroids, grid laser is reserved for focal macular edema and surgery is indicated in case of vitreous hemorrhages or retinal detachment.
Austin J Clin Ophthalmol - Volume 8 Issue 1 - 2021 ISSN : 2381-9162 | www.austinpublishing group.com Khanaouchi et al. () All rights are reserved
Citation: Khanaouchi N, Mouzarii Y, Reda K and Oubaaz A. Hemi Retinal Vein Occlusion a Particular Form of Retinal Vein Occlusion. Austin J Clin Ophthalmol. 2021; 8(1): 1117. 


\section{References}

1. M Rehak, $P$ Wiedemann. Retinal vein thrombosis: pathogenesis and management. J Thromb Haemost. 2010; 8: 1886-1894.

2. La Spina Carlo, et al. "Practical management of retinal vein occlusions". Ophthalmology and therapy. 2012; 1: 3.

3. Sohan Singh Hayreh, Manmohindar Singh Hayreh. Hemi-Central Retinal Vein Occlusion Pathogenesis, Clinical Features, and Natural History. Arch Ophthalmol. 1980; 98: 1600-1609.
4. Chopdar A. Hemi-central retinal vein occlusion. Pathogenesis, clinical features, natural history and incidence of dual trunk central retinal vein. Trans Ophthalmol Soc UK. 1982; 102: 241-248.

5. Kolar P. Definition and Classification of Retinal Vein Occlusion. International Journal of Ophthalmic Research. 2016. 